Supporting information for:

\title{
Glassy Carbon Electrode Electromodification in the Presence of Organic Monomers: Electropolymerization versus Activation
} Ali M. Abdel-Aziz, Hamdy H. Hassan, Ibrahim H. A. Badr*

Chemistry Department, Faculty of Science, Ain-Shams University, Cairo 11566, Egypt

*E-mail: ihbadr@sci.asu.edu.eg, ibadr1@gmail.com 


\section{Table of Contents}

Figure S1. Successive cyclic voltammograms (20 cycles) of GCE in 0.1 M PBS ( $\mathrm{pH}$ 7.0): in absence of any monomer (a), presence of $2.0 \times 10^{-3} \mathrm{M} p$-ABSA (b), or $5.0 \times 10^{-3} \mathrm{M}$ L-cysteine (c). Scan rate: $100 \mathrm{mVs}^{-1}$

Figure S2. Deconvolution of G-bands of Raman spectra of AGCE (a), GCE $E_{b}(b)$,

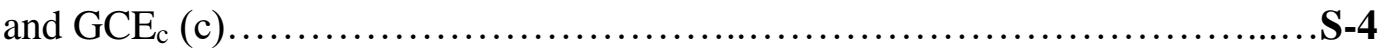

Table S1. The FT-IR spectroscopic data of the possible SFGs at AGCE S-5

Scheme S1. A proposed electrooxidation mechanism for glassy carbon electrodes at high anodic voltage

Figure S3. EDX spectra of $\mathrm{GCE}_{b}$ and $\mathrm{GCE}_{\mathrm{c}}$ after treatment with more electrochemical scans

Figure S4. (A) CVs of AGCE at different scan rates in $0.1 \mathrm{M} \mathrm{KCl}$ containing 5.0 $\mathrm{mM}\left[\mathrm{Fe}(\mathrm{CN})_{6}\right]^{3-14}$. Scan rates from 50 to $1000 \mathrm{mVs}^{-1}$. (B) Plot of anodic peak current $\left(i_{p}\right)$ versus the square root of the scan rate $\left(v^{1 / 2}\right)$ S-8

Figure S5. Nyquist diagrams obtained at AGCE (a) and UGCE (b) in $0.1 \mathrm{M} \mathrm{KCl}$ containing $5.0 \mathrm{mM}\left[\mathrm{Fe}(\mathrm{CN})_{6}\right]^{3-14}$. The frequency range for impedance measurements were from $20 \mathrm{mHz}$ to $100 \mathrm{kHz}$ with AC voltage amplitude of $7 \mathrm{mV}$ RMS. The inset is the equivalent circuit, $R_{s}$ represents the solution resistance, $R_{c t}$ represents the charge-transfer resistance, $\mathrm{W}$ represents the Warburg impedance, and a constant phase element (CPE) is substituted for the double-layer capacitance (Q)

Figure S6. The calibration plots for DA at AGCE (A) and $\mathrm{GCE}_{b}(\mathrm{~B})$. The insets indicate the responses at low concentrations of DA 


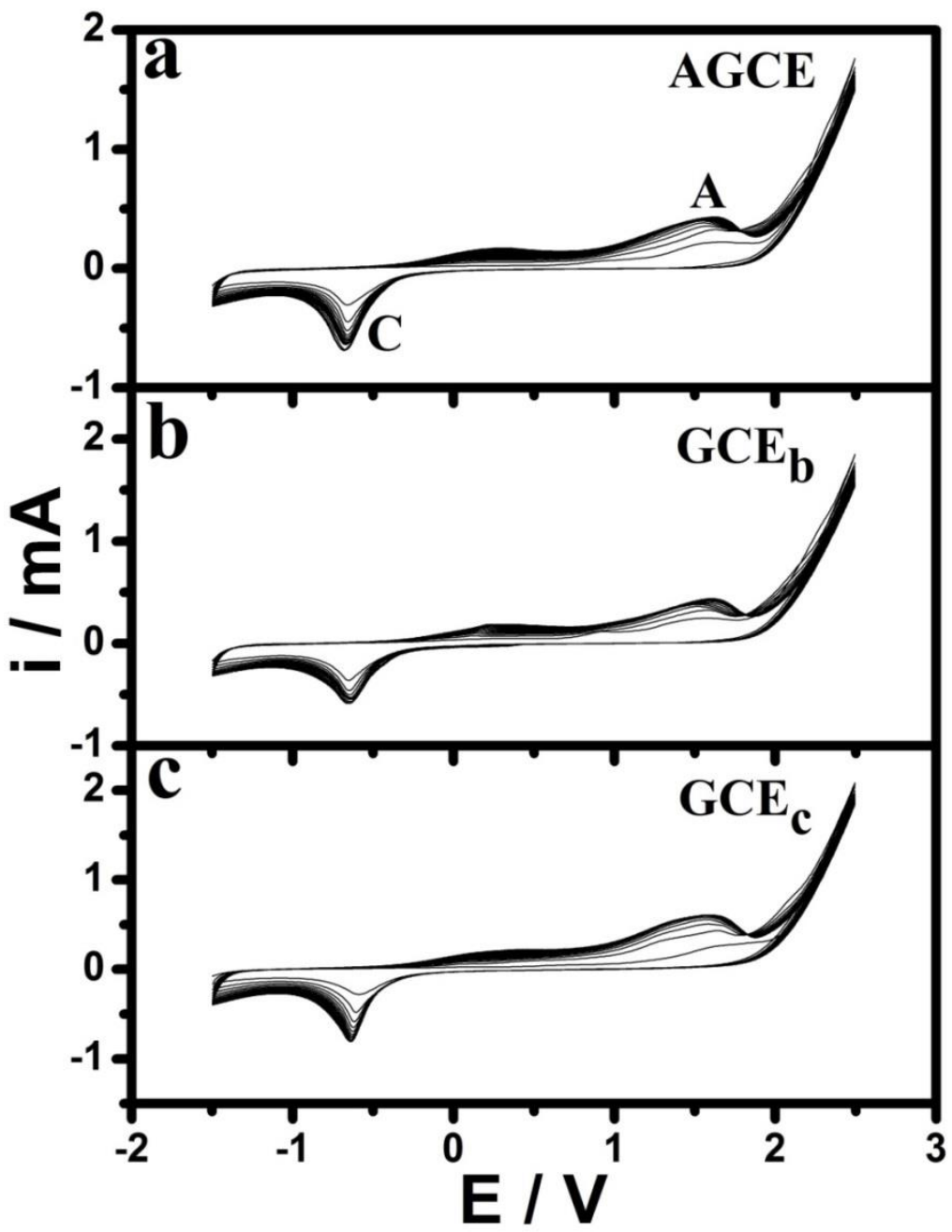

Figure S1. Successive cyclic voltammograms (20 cycles) of GCE in $0.1 \mathrm{M}$ PBS (pH 7.0): in absence of any monomer (a), presence of $2.0 \times 10^{-3} \mathrm{M} p$ -

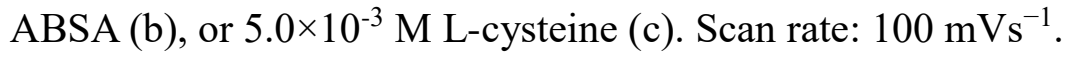

Page S-3 


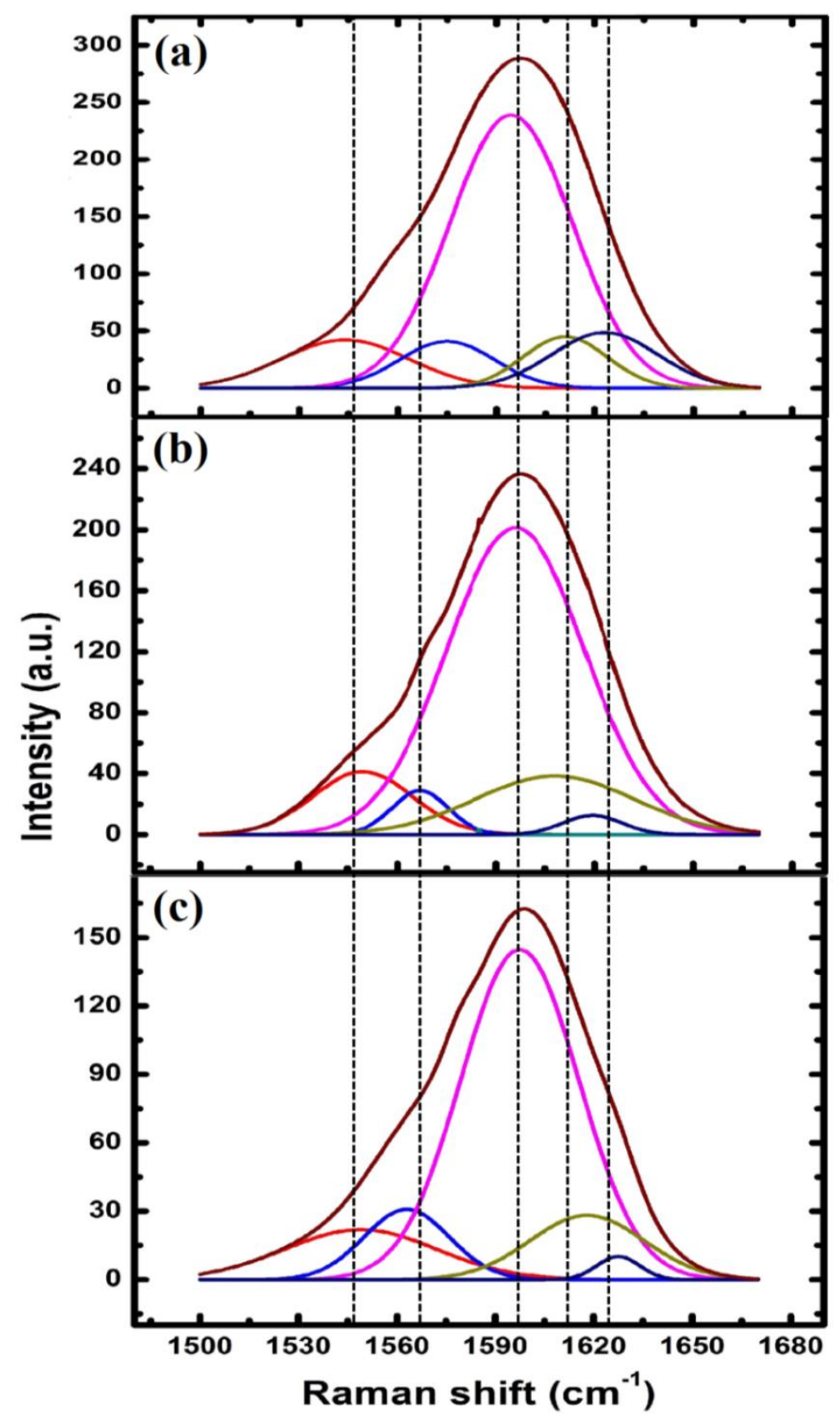

Figure S2. Deconvolution of G-bands of Raman spectra of AGCE (a), GCE and $\mathrm{GCE}_{\mathrm{c}}(\mathrm{c})$.

Page S-4 
Table S1. The FT-IR spectroscopic data of the possible SFGs at AGCE.

\begin{tabular}{|c|c|c|c|}
\hline Group number & Function group & Structure & Frequency $/ \mathrm{cm}^{-1}$ \\
\hline 1 & Edge hydroxyl & $\mathrm{R}-\mathrm{OH}$ & \multirow{3}{*}{$\geq 3000$} \\
\hline 2 & Basal hydroxyl & $\mathrm{R}-\mathrm{OH}$ & \\
\hline 3 & Free phenolic hydroxyl & ph-OH & \\
\hline 4 & $\begin{array}{l}\text { Carboxylic-hydroxyl (characteristic } \\
\text { band) }\end{array}$ & $-\mathrm{COOH}$ & \multirow{2}{*}{$2750-3000$} \\
\hline 5 & Phenolic hydrogen-bonded hydroxyl & $\begin{array}{c}\mathbf{H} \\
\mathbf{l} \\
\mathbf{p h}-\mathbf{O}--\mathbf{H}\end{array}$ & \\
\hline 6 & Carbon dioxide & $\mathrm{CO}_{2}$ & $2200-2300$ \\
\hline 7 & Lactone & & \multirow{3}{*}{$1710-1800$} \\
\hline 8 & Acid derivative & RCOX & \\
\hline 9 & Ketone & RCOR & \\
\hline 10 & Carboxylate & $-\mathrm{COO}^{-}$ & \multirow{2}{*}{$1550-1690$} \\
\hline 11 & Quinone & & \\
\hline 12 & Etheric linkage & $\mathrm{C}-\mathrm{O}-\mathrm{C}$ & \multirow{2}{*}{$1040-1150$} \\
\hline 13 & Carbon-hydroxyl bond stretching & $\mathrm{C}-\mathrm{OH}$ & \\
\hline 14 & Epoxide, cyclic peroxides & & 1250 \\
\hline
\end{tabular}





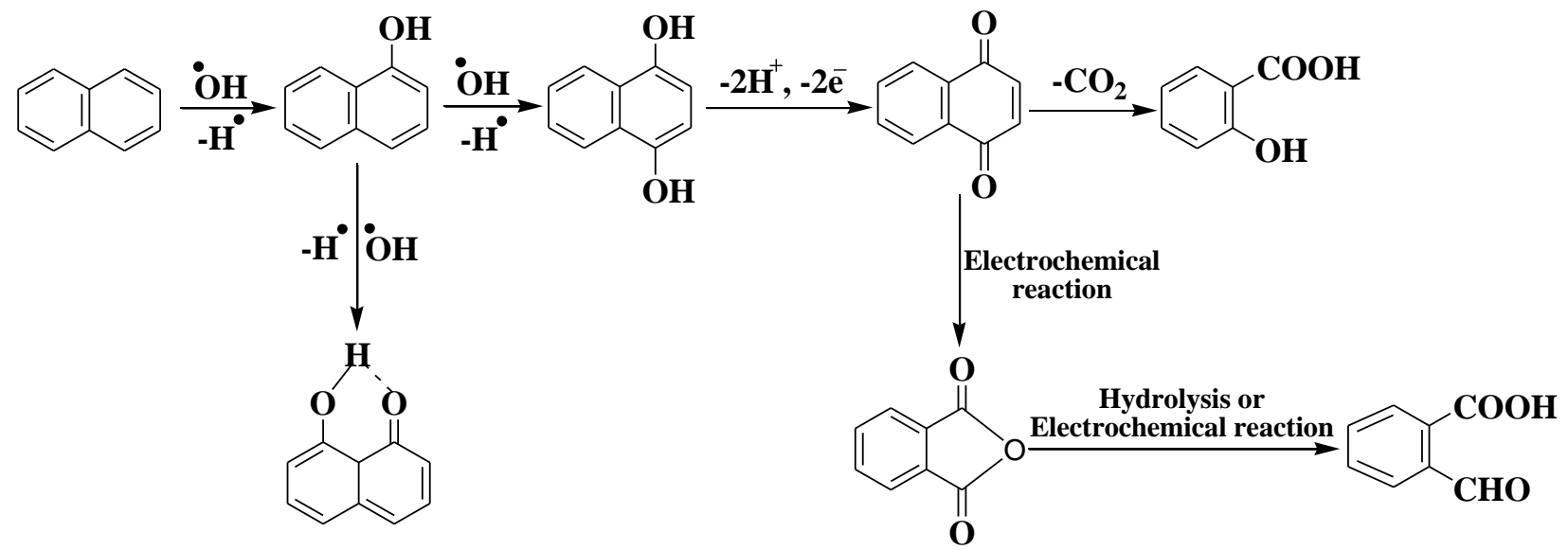

Scheme S1. A proposed electrooxidation mechanism for glassy carbon electrodes at high anodic voltage. 

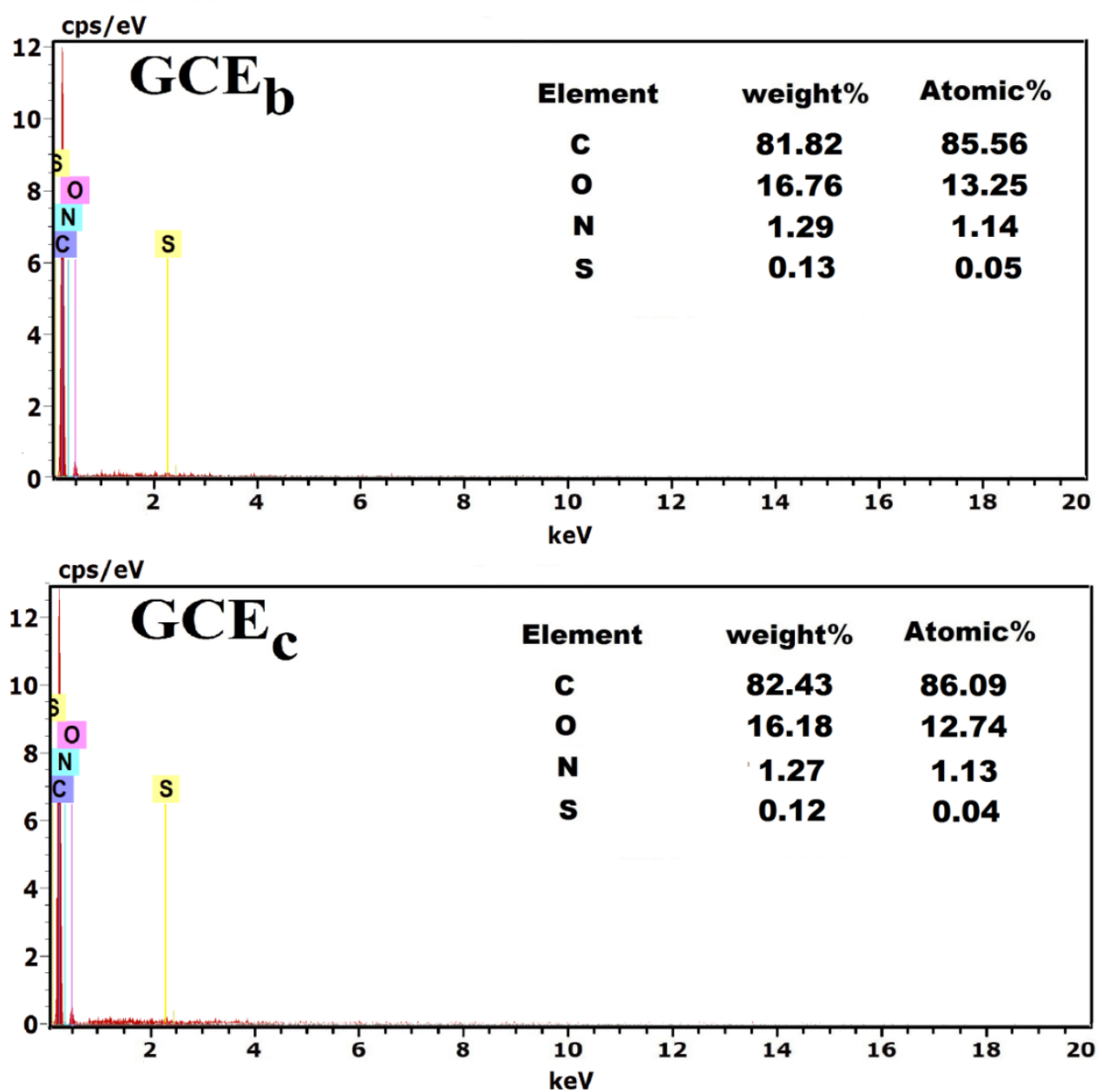

Figure S3. EDX spectra of $\mathrm{GCE}_{b}$ and $\mathrm{GCE}_{c}$ after treatment with more electrochemical scans ( 20 cycles).

\section{Page S-7}



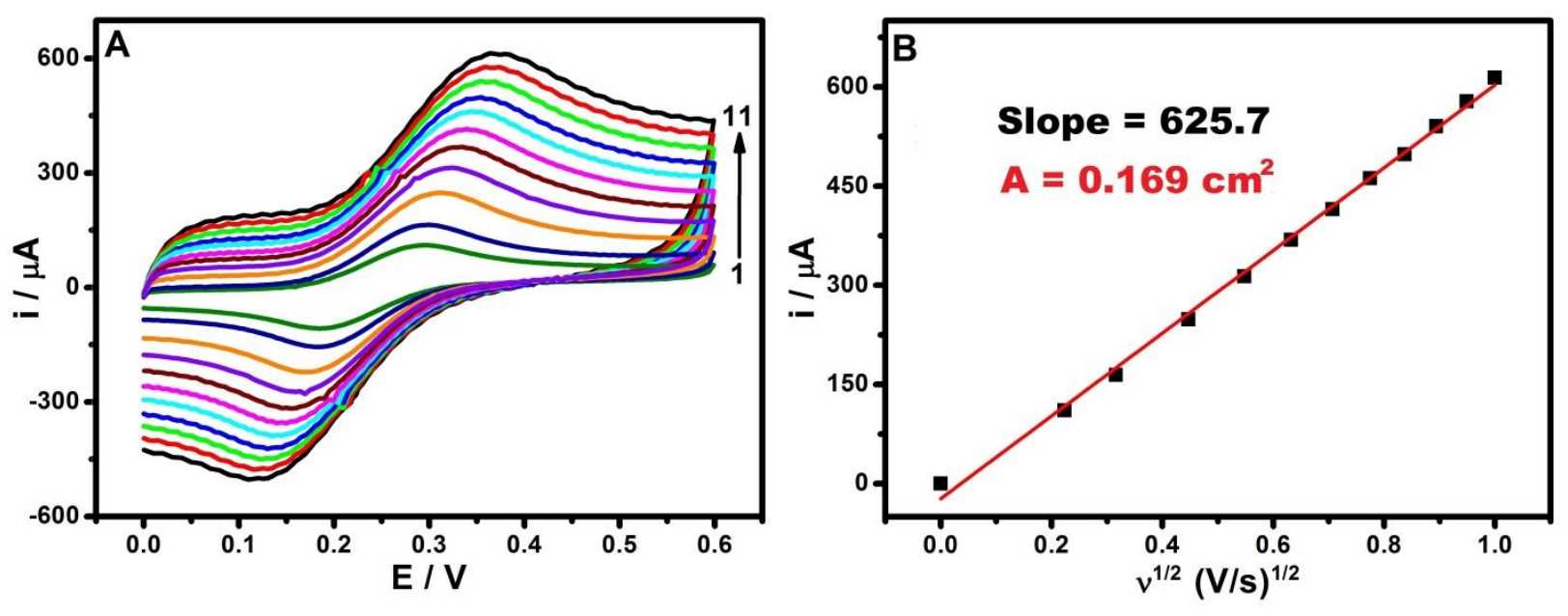

Figure S4. (A) CVs of AGCE at different scan rates in $0.1 \mathrm{M} \mathrm{KCl}$ containing 5.0 $\mathrm{mM}\left[\mathrm{Fe}(\mathrm{CN})_{6}\right]^{3-14}$. Scan rates from 50 to $1000 \mathrm{mVs}^{-1}$. (B) Plot of anodic peak current $\left(i_{p}\right)$ versus the square root of the scan rate $\left(v^{1 / 2}\right)$. 


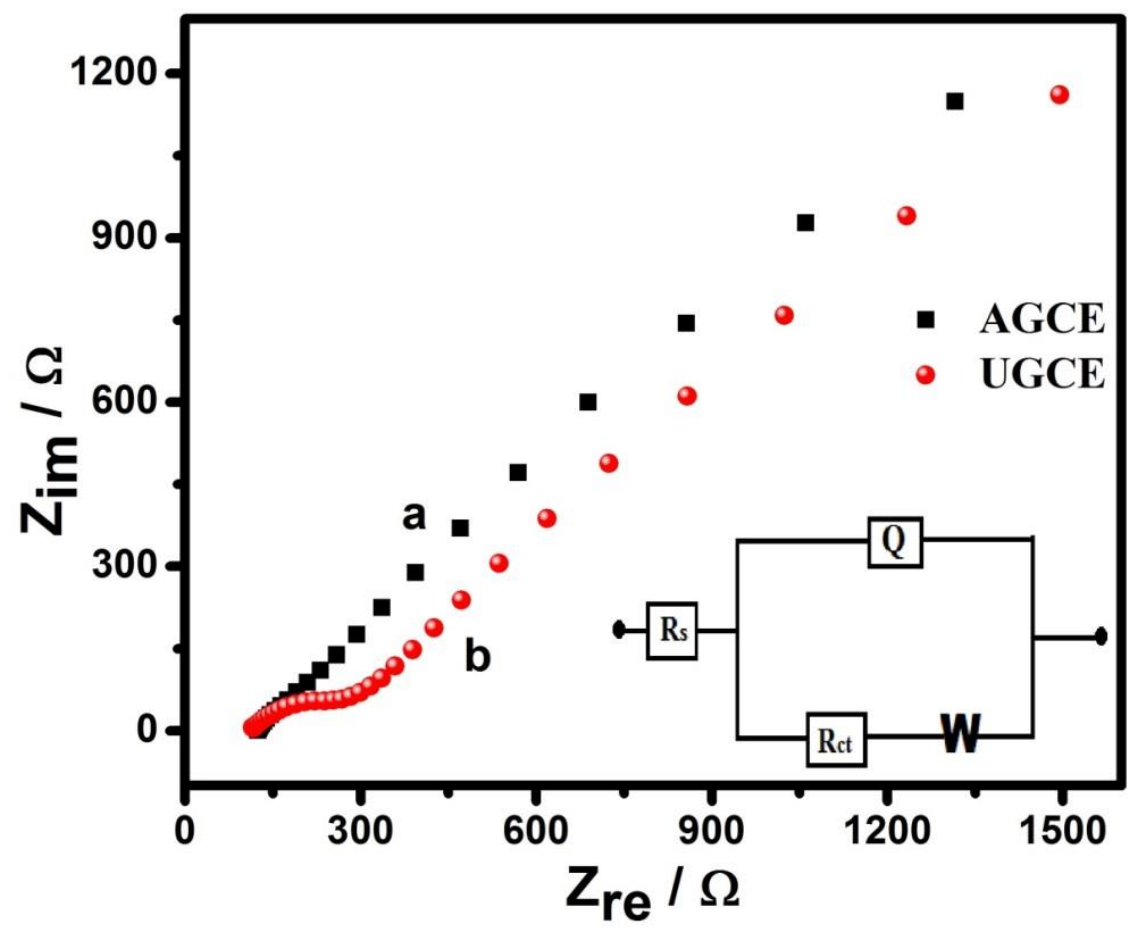

Figure S5. Nyquist diagrams obtained at AGCE (a) and UGCE (b) in $0.1 \mathrm{M}$ $\mathrm{KCl}$ containing $5.0 \mathrm{mM}\left[\mathrm{Fe}(\mathrm{CN})_{6}\right]^{3-/ 4-}$. The frequency range for impedance measurements were from $20 \mathrm{mHz}$ to $100 \mathrm{kHz}$ with $\mathrm{AC}$ voltage amplitude of $7 \mathrm{mV}$ RMS. The inset is the equivalent circuit, $R_{s}$ represents the solution resistance, $\mathrm{R}_{\mathrm{ct}}$ represents the charge-transfer resistance, $\mathrm{W}$ represents the Warburg impedance, and a constant phase element (CPE) is substituted for the double-layer capacitance $(\mathrm{Q})$. 

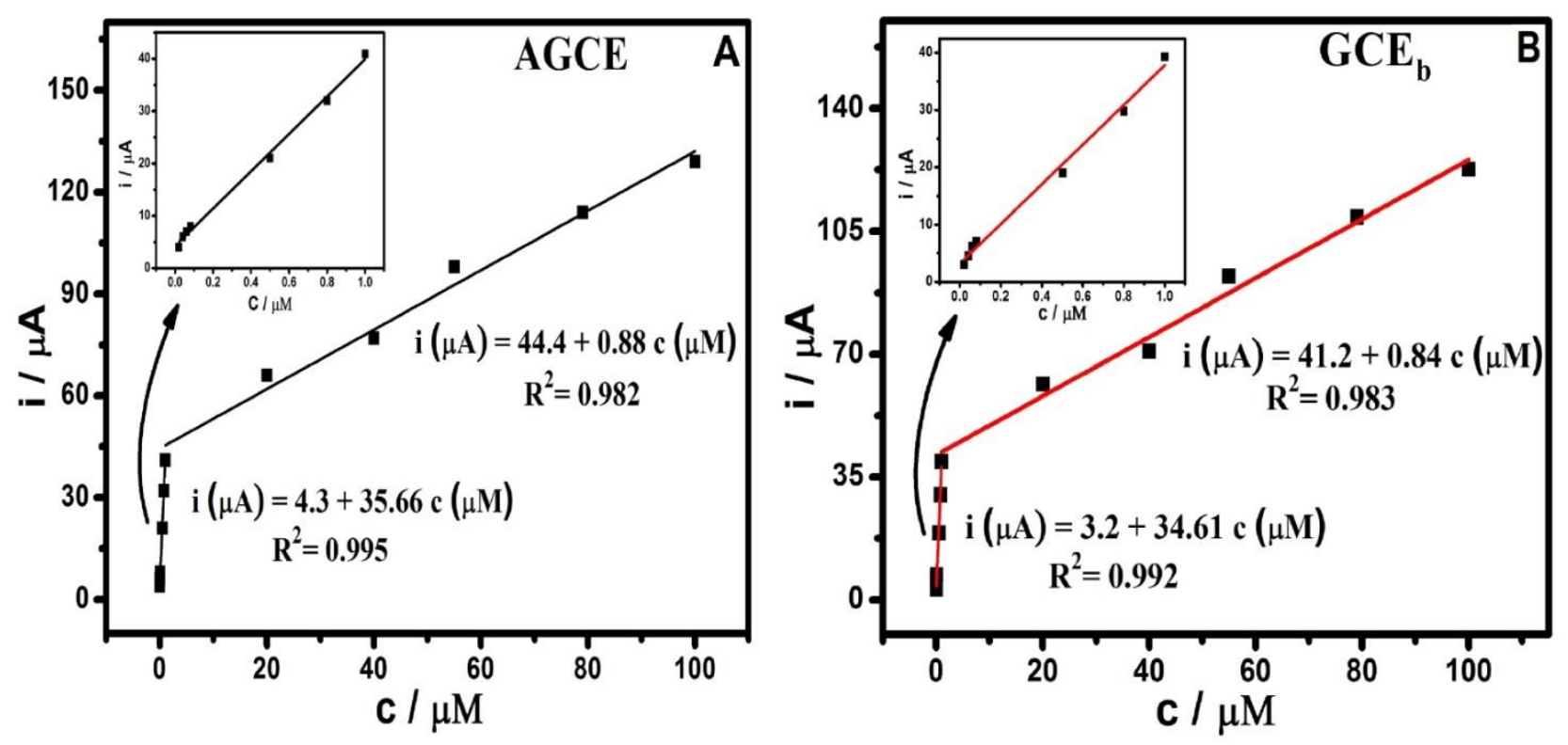

Figure S6. The calibration plots for DA at AGCE (A) and $\mathrm{GCE}_{b}(\mathrm{~B})$. The insets indicate the responses at low concentrations of DA. 